\title{
Unraveling the Cross: Communicating beyond Group Mind Education
}

\begin{abstract}
My $\mathrm{PhD}$ research focused on the metaphor or symbol cross to unravel the dynamics in crosscultural education. Though an intuitive choice, I felt a focus on the cross-metaphor was timely for its religious connotations that seems to powerfully affect world politics including globalising education with constructs such as 'sin, guilt and other mistakes as part of an energy process, not the fault of individuals' (Bethe, 2008). Whilst the cross metaphor seems to lead its own life, it is promulgated by a group mind that is rarely acknowledged and subliminally reinforces the idea that humankind has no sensory relationship with earth-bound and celestial forces, with dire consequences. Perhaps the most exciting result from the study was its capacity to bring back to life an ancient universal symbol that, over time, had lost its dynamic meaning. All those involved in the study learned that we are not free to the extent that we identify with the part of mind that is structured in time and space, which sees subjects and objects but also symbols as separate from meaning-making systems. We recognised the cross as something other than static. Provided it is recognised as such, the cross is a medium, a facilitator, a dynamic flow that propels humanity forward as it rehabilitates the self-inrelationship.
\end{abstract}

Key words: cross-metaphor, group mind, sensory self, evolving cross-cultural education

\section{Introduction}

In this paper I discuss that and how a focus on the metaphor or symbol CROSS reveals a range of dynamics that pertain to cross-cultural education. Especially highly perceptive or sensitive people who work in cross-cultural contexts and tend to be misunderstood and sidelined in autocratic discourses may benefit from exploring these dynamics as part of a culturally competent practice.

For cross-cultural education as a systemic whole, it remains to be seen whether and how it will move through and out of its own 'gate-keeping' dynamics that counteract the need to emerge from that what Apple (2006) calls 'the play-ground of victimhood as a powerful rhetorical device in the reinforcing of power-dynamics (p. 165). This article does not seek to interfere with a process that can only take place of its own accord. But it does seek to stimulate in the reader some kind of recognition of the human ability to distinguish the area of the higher moral ground from that what simply is (in ethics).

\section{Context of the $\mathrm{PhD}$ research study}

So what type of cross-cultural education is preferable in the context of the current transition from industrialization to ecological thinking and the related meltdown of three disintegrating systems involving the economical, environmental and psycho-social (Gidley, 2007, p. 7)? My $\mathrm{PhD}$ study was premised on and revolved around this question, reflecting on the notion of 'right educators' (Krishnamurti, 1978) as people who practice vulnerability in dialogue (Bohm, 1996) rather than techniques, encourage double-loop learning that in contrast to single loop learning 'involves questioning the role of the framing and learning systems that underlie actual goals and strategies' (Smith (2001/2009) and vision development. They focus on intention and attention rather than rules, policies and procedures. 
My own background as a teacher in Expression \& Communication had shown that teaching/ learning/ researching - also in cross-cultural contexts - is one and the same activity if considered a dynamic-in-interaction because the self is always in relationship. It is a learningin-action as one goes, but also a learning-style that contrasts sharply with that of the contemporary global educational scene and its dictates and principles that resonate a 'higher moral ground'. This scene demonstrates little respect for and interest in the self-inrelationship. A lot of investment is placed in competing positions and viewpoints and there is little evidence of any awareness of better ways than the thriving on 'being right' born from the need to win at all cost. Like in politics, a 'right' education (Apple, 2006) is obsessed with death- rather than life-oriented dynamics.

Because I found myself ill-at-ease with those dynamics and could not find any literature that gave me a sense of 'permission' to feel this way, I wondered how a sample of other holistically oriented cross-cultural educators experience and deal with these - what I consider to be - disturbing dynamics. With 'holistically oriented' is meant an understanding of the fact that all the properties of a given system cannot be separated from its parts.

A five (5) year long, qualitative $\mathrm{PhD}$ research study ensued. Nineteen (19) holistically oriented cross-cultural educators from the Netherlands and Australia volunteered as research participants. The study involved three (3) semi-structured face to face interviews and three (3) focus-groups. They took place both in the Netherlands and on the East-Coast of Australia.

I formulated the following question: How does a sample of holistically oriented educators understand and work with complex dynamics as they teach and learn across cultures? Subsidiary questions that helped to clarify the problem were: 1/ How do cross-cultural educators approach the crix of the matter, where the split or the divide, or in terms of chaos theory bifurcation, is experienced? 2/ How is the split contextualised as a web and the dynamics that support it? 3/ How might wholesome life ecology re-energise understanding among human beings and the ability to work with complex dynamics in a cross-cultural context?

\section{Bricoleuring my way around}

My experiences as a teacher in an Aboriginal school in The Tanami Desert of Australia showed that the self-in-relationship negotiates cross-cultural education as a systemic 'landscape' that is best negotiated by applying bricolage as a methodology so as to find one's way around and tinker at the edges of existing paradigms and structures by employing the means at hand - so a mixture of tools - to get a desired outcome.

From the thesis (Van den Akker, 2009, p. 7):

I am writing a thesis on cross-cultural education and crossing communication barriers. And I wonder how to speak a thousand words with a few? Why use words when Silence and images speak so much clearer? Expressing and communicating dynamics, including feelings, not emotions but feelings, is what I seek. Sensations have colours and 'sounds' to them that sometimes 'hit' us, in ways that a world that thinks in terms of adding up, dividing and multiplying does not acknowledge. Feelings are another side of language; a language known across cultures: felt experiences that cannot be expressed in words except poetically.

So I make a filmic impression to express and communicate dynamics; a felt experience of what is often left behind ... 
The CROSS metaphor functioned as a kind of compass through a territory that some research-participants defined as 'something that comes from the heart' and that cannot be defined. It responded positively to criticisms from holistically oriented theorists and practitioners who suggest that resistance to multi- and interdisciplinary approaches is defeatist and that the concept of culture needs to be seen as something fluid or gaseous, not static. Carr (2011) for example believes that non-local consciousness in some way plays a part in everything we do. According to him, 'it plays a huge part (mostly unconsciously) in how we navigate through our lives. [But] wide-spread skepticism has prevented most people (beyond pre-rational) from exploring and understanding the incredible implications of nonlocal consciousness in all aspects of life'. The question then is, how can skepticism do this preventing? Perhaps most people have a strong sense of wanting to belong to one group or another and 'fit in', and perhaps especially so highly perceptive or sensitive people. But the dominant landscape with 'harsh' dynamics associated with reduced expenditure and effectiveness (economy) side-lines and ignores the 'sensitive' as witnessed in an education that focuses on profit (Nussbaum, 2011), and produces generations of useful machines rather than complete citizens (ibid). Especially sensitive people - perhaps more than any others need to free themselves from what others think (Hogeweg, 2011) as they move away from first tier group mind dynamics where 'sides stick' (Dimitrov, 2005) and 'weerbarstigheid' [fractiousness, stubbornness] (Van Hoorn, 2007) blocks a transit into second tier stages of development.

I will contextualise the concepts of group mind in the remainder of this paper, but first I would like to shed light on the term 'second tier' which refers to Beck \& Cowan's Spiral Dynamics (1996/2006) and is inspired by the works of Ken Wilber. Wayne Carr (2011) describes second tier people as human beings who "can share the same reality space much more easily and deeply because have less "overlay" and fewer "read-ins" on top of what is. When second tier people meet, there is more of a convergence (or perhaps "metaconvergence") of points of view (rather than being spread all over the map with points of view that tend to cancel out each other and create stalemates)'. From a second tier (integral) cross-cultural perspective, contemporary cross-cultural education is not fixed in disciplines, courses or theories. It is an evolving practice. Second tier people apply the sensory self and intuition in an evolving pedagogy that aims to transform disembodied, violent dynamics. The sensory self and intuition like Aboriginal people's sensitivity to geomagnetic currents is nothing less than an intelligence that guides them like a compass. Disembodied viewpoints can attack and defend but they always originate in and build upon historic mental pictures and iconic knowledge (Bohnsack, as cited in Van den Akker, 2009, p. 9). They are quite separate from the sensory self and intuition and increased awareness of this separation is recommended so as to be liberated from the globally accepted dictate of 'cultural competence': a dictate that focuses on thus strengthens existing power-dynamics. Furthermore, awareness of that separation gives space to sustainable practices where people's aspiration, inspiration and sensory communications between the human and the non-human worlds are validated and encouraged.

\section{Group mind and the 'fixed' cross as metaphor for the current state of cross-cultural education}

As an offshoot of mainstream education, most cross-cultural education and training programs are positivist and functionalist in orientation and both create and deliver only a story. They focus on historical data and build and depend upon reactivity, not responsibility in the present moment. Most programs are guided by a curriculum that is typically designed by others than those who deliver them. As Eisner (1972) pointed out, educational designers tend to exclude 
themselves from the road that others are to walk. They extricate themselves as if separate from all of life in the present moment. They dwell in the repetition of a paradigm that necessarily denies the self-in-relationship and the sensory self that is best explored, experienced and observed as a just-ism with principles that are inhered in all of life.

Dwelling in this repetition is a consequence of ignoring group mind. Group mind protects egotistical and delusional dynamics that we witness in debates where either/or, right/wrong and true/false thinking dominates. The vehemence of this protection is demonstrated for example in the demand for policy to dictate outcomes (Eisner, 1972). It is also evident in the 'academic divided self' (Bochner, 1997) that is exalted through 'the voice of reason, objectivity, and rigor, with the personal self behind a veneer (p. 433). The need to self-protect is seen when the capriciousness of the immediate experience is annulled (ibid, pp. 421-422). Group mind automatically repels human dynamics of enlightenment. E.g. self-inspection, dialogue, creativity, communication and inspiration are last on the priority list. As such group mind reinforces a false sense of safety and protection, culminating in a frosty landscape of cross-cultural relationships.

Group mind can also be described as a web of relationships. Such webs, as Thompson (1996, p. 126) suggests, are dynamic in that they adapt to an ecology that either compresses attention (a fixation within limits) or focuses attention (creatively expands into a new space). Group mind consists of cumulative movements in each single motion that have consequences which open up a new bifurcation and move either upwards to a new culture of a higher spirituality, or downwards towards darkness and entropy. To be become less controlled by automatic forces, Thompson (2004) argues that people are to consider the current level of consciousness that has 'become the biggest obstruction to the continuity of human existence' (p. 10).

Group mind is a concept that was first introduced by Ormsby-Green (2007a). He defines it as 'an aggregation of combined caseloads of a number of people which sets up an 'entity' and seems to have a sentience and a will of its own. Entirely reactive, combining people under commonly connected caseload. Apparent in instances of mob rule, religious euphoria, societal judgmentalism, group fanaticism, and ideological fervour as typically seen in various religions, cults, belief systems and politics' (p. 181).

I wrote the following poem during my work in an Aboriginal community in the Tanami Desert, in May 2000:

\section{GROUPMIND}

Guilt when not abiding by invented rules

Shame you should feel: Stay part of us We'll protect you from danger.

Say sorry and we'll forgive you.

Don't speak for or against us.

We sort our own stuff out and keep secret what We want to withold from you.

We'll love you if your actions agree With ours Otherwise abandonment

Or we'll bring in the law-enforcers.

For groups' sake, Amen. 


\section{Recognising group mind}

It is useful for cross-cultural educators to know that group mind can be recognised. Recognition takes place in the realm of the spirit, also considered the 'native', uncorrupted being and the unit of ultimate awareness (Ormsby-Green (2007a, p. 18). Recognition is not cognition, but similar to crossing which is an understanding, a sense of many implications at once. The crossing is what makes us say "Aha, that's how it goes' (Gendlin, in Levin, 1997, p. 29). Ormsby-Green (2007a, p. 147) points out that the word cognition assumes 'the illusion of gaining realisation or perception' whilst the word recognition acknowledges that everything we have is already known, though not necessarily consciously available. We may have lost sight of something or it may have been inaccessible to us for some time, and we can rediscover it, sometimes in its entirety so that we experience 'a return of understanding' (ibid, p. 227).

Recognising group mind helps cross-cultural educators in bootstrapping their way out of the first tier group mind and its established (fixed) ways of knowing, doing and being to emerge into the second tier as a self-in-relationship. Theoretical knowledge, or knowing about cultural competence through critical praxis alone does not assist that process, despite what some (first tier) cross-cultural experts may claim. Theoretical knowledge does not improve communication, but recognition does. Jack Cohen's (2001) maxim 'Ignorance recognised is the most valuable starting place' (p. 15) then teems with insight from the understanding that ignorance does not imply arrogance but unawareness. In the words of Tandon (1995/2005, p. 4): ignorance means 'the [wrong] cognition of the eternal, the pure, the pleasant and the self in the non-eternal, the impure, the painful and the not-self'.

\section{Methodology}

The qualities of sustained attention and embodied presence can open into subliminal layers where there is an expansiveness that can hold whatever is arising in the mindbody

Sills \& Lown, 2008

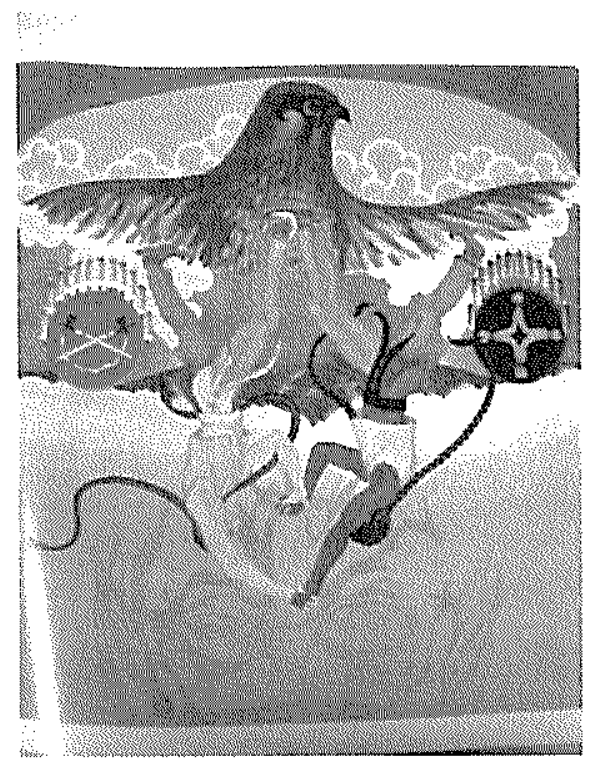

Image from Storm's (1972) book 'Seven Arrows' 
In an attempt to recognise my own ignorance to the highest possibly degree, and as I bricoleured my way around in the moment of research, I was deeply aware of the projection/reflection principle which refers to the fact that whatever we receive from the physical universe is a reflection of what we have within, and that which we put out reflects back for us to experience (Ormsby-Green., 2007b, p. 23). I looked for ways to weave 'my story' in with that of the larger community, trusting that my account of the 'interwoven' self would expose the deeper layers of the collective psyche that 'weaves' the plot and subsequent dynamics as a self-organising entity, like a spider weaves its own web of relationships. I noticed that patterns of repetition function to create a sense of coherence and a coming to grips with chaotic forces or sources of power and authority that are not under our immediate control (Schneider, 2008, p. 14). As the filmmaker Bill Viola in for example 'The greeting' (1995) made explicit, there is a lot to be learned from confronting repetition: the static and the moving worlds become visible as overlapping interactions. Here I found bricolage (Kincheloe \& Berry, 2004) to be a most liberating methodology alongside the production of a continuous and growing intersubjectivity and multisensory experience that took the shape of an autoethnographic account.

Thinking performatively is about putting aside that analytical part of ourselves that normally deals with data and such, and moving to the other side of the equation and getting in touch with that earlier place where we were energized by the data itselfhow it was sparking ideas that were coming from our own personal experience which, every creative person will tell you, is the fountain of all creativity. It's also about communication; it's about how we are going to develop our skills in collaborating with someone who is speaking a different language, coming from a different background; going through that learning process is almost as important as the end product itself.

Gergen \& Jones, 2008, p. 4

Thinking performatively allowed me to stay alert and alive in the midst of action rather than partake of ideals that do not exist. It allowed me to use the means at hand and 'destroy the mystique of the engineer' (Benterrak et al, 1984, p. 149) in respect of 'Indigenous knowledge that is to be shared as something relational and as something shared with all creation including animals, the cosmos, plants and the earth' (Wilson, 2001, as cited in Wilson, 2008, p. 74). I was able to witness first-hand interconnections that are usually hidden within the group mind whilst autoethnographically giving space and voice to both my researchparticipants and my own lived experiences, all in the context of broader cultural and subcultural processes (Hockey \& Collinson, 2006; Hockey, 2006).

As a whole, then, my PhD study became a form of self-study that can be helpful to raise particular questions to drive educational change (Hamilton, Smith \& Worthington, 2008, as cited in Van den Akker, 2009, p. 13). The heart of cross-cultural education turned out to be a shared journey that is best expressed and communicated as a narrative to activate subjectivity and emotional response and offer lessons for further conversation (Ellis \& Bochner, 2003, pp. 217-218). By concentrating on the shared space where individually adopted but collectively produced paradigms collide, the face and voice of cross-cultural contexts was revealed in all its dynamics.

\section{Unravelling the CROSS}

From the point of view of semiotics, all forms of signs make it possible to reveal the differences and similarities between the individual forms. The latter use of signs is important when studying fractal properties of complex systems. As far as fractals are similar structures which repeat at different levels (scales), it makes sense to extract 
signs pointing to the similarity between fractals belonging to different levels, to estimate the strength of this similarity, and to explore how this strength varies when moving from one fractal level to another. Signs are rarely interesting in and of themselves, but in terms of what they stand for. They are not data to be verifies as to whether they are true or not, but are instead clues about what various things and circumstances could mean.

Dimitrov, 1998

In the research-process it became increasingly clear that an unravelling of the CROSSsymbol gave life to a tacit knowledge of the existence of dynamics (Dimitrov, 2005) that are energy forces (p. 1) and also manifest in and as human dynamics. Human dynamics interact with the dynamics of the minerals, plants and animals, and all interact with the macro scale of the universal dynamics and the micro scale of quantum dynamics (ibid).

Participants talked in 'murky' ways and by use of metaphor, relating to the CROSS as more of a lived experience. They consulted their emotions, logic and sensations to move with, forward and backward between past, present and future, as if directed by an 'inner compass' towards a blurry though 'certain' outcome. They recognised a group mind with religiously/culturally reinforced mechanisms such as blames, expectations, attachments, significances, criticisms, finger pointings, protests, give-aways, buy-ins, beliefs, viewpoints, intolerances, denials, assumptions and limitations. They recognised how cross-cultural education remains 'paradigm-closed' (Beck \& Cowan, 1996, p. 158).

Some participants spoke about the cross in terms of 'seeing as a camouflage', whilst others associated it with a river that is crossed by a bridge. Ros was an Indigenous researchparticipant who described the 'cross' as follows:

Ros: I mean, I think some people would be quite... like oh is that how we make you feel? But no it's not. That's how I believe the system makes me feel. Not necessarily people. This is not about people. It is about the system that determines how people act and think because 'these are the guidelines we've put together.' And the system is powerful. So I say: What does she look like? And they say: Who? I ask, is it a he or a she? They say: Who? I say: The system! Does she have blood? I don't think it is a he or a she! Why is everybody so fearful of something that is cold, that has no heart, that is a nothing? Why don't people look like people with a heart, with bodies, that have feelings that can commit? People are so fearful of this system-thing. And so that's why I often say, what does she look like? Is it a he or a she or what? You're nuts! But no. The fear of the system is so prominent. Yet, you cannot put the finger on what this thing is. It's like a window that people look out of, to keep them from...

Jose: From engaging...?

Ros: Yeah. You know... I wonder if they value what I have to say. Because I am who I am, a Maori-woman, who represents other Maori women... I wonder if they're interested in that, or are they interested because I might have something different to say that they have not heard yet...

Participants and I explored the metaphor CROSS not only as a process and metaphor, but also as a shape it being one of the four (4) central shapes that have been central to all cultures for as long as we know of humanity's existence: the dot, the circle, the cross and the square (Chevalier \& Gheerbrant, 1996). From an integral research perspective it was interesting to find that the visionary Rudolf Steiner (2007) stressed the import of engaging with geometric 
shapes especially when people's minds are caught in materialism. The idea resonates with the words of the Danish biologist Hoffmeyer, who said that 'life is based entirely on semiosis, on sign operations. The living world ... can be awe inspiring or deeply moving and, whatever else it may be, it concerns us. It is made of the same stuff as we ourselves are - it resembles us because it dreamed us up' (as cited in Bird Rose, 2008, pp. 158-159).

As noted previously, the cross is an ancient symbol, though over time it has been signified in different ways. Literature-research demonstrated that people adhere to a range of religions and/or other doctrines and have signified the CROSS in a range of ways, including:

- The Celtic Cross,

- The Ankh symbol

- The double bar cross

- The T (the Tau-cross, used by for instance the Druids and nowadays again in quantum mechanics).

- The + (the Christian cross, or crucifix)

- The X (by the 'Good Men' or Gnostics, but also the Nazis and the Jewish peoples). In the Western world (with at its root the Christian religion) the $-\mathrm{X}$ - signifies multiplication.

- Then, with a bit of imagination, the vertical axis can pull down the horizontal arm of the T-cross, so a Y-shape emerges which in the Jewish religion symbolizes Yahweh.

- When a 'downward pushing' force 'cracks' the Y-shape at the intersection, an upwards pushing flow can split the $Y$-shape further into 2 . The sides then open up as ) ( or as ] [, signifying a bridge or a tunnel. When these sides separate out further in timespace (the universe expands) the attachment in the space between dissolves and two completely free entities emerge. Should a sense of attachment remain, we can visualise an $\mathrm{H}$.

As a whole, participants felt relieved and refreshed after talking about the 'cross' and especially the dynamics at the Heart of the Cross. The talking appeared to open up the feeling or sensory body. In a metaphorical sense, it was as if the fixed cross transformed into a dynamic one. It unfolded into an hourglass-shape through which time and space flows in its own pace and place.

\section{Concluding analysis and synthesis of the data}

It is hard to capture in a few sentences all the different dynamics that became apparent in the study (Van den Akker, 2009, p. 189). But crudely it could be concluded that:

$1 /$ contemporary cross-cultural education is dominated by a shared academic culture where scholars from all over the world concentrate on what are considered 'higher' mental functions, meaning cognitive skills. The supposedly 'lower' mental yet universal functions such as sensing (visual, auditory, kinetic) and aesthetic perception (such as colour, movement, pattern, balance, tone) are devalued, ignored and denied. Yet, these 'lower' mental functions are exactly the functions which holistically oriented cross-cultural educators apply to be able to understand and work with complex dynamics. They build on 'uncertain' skills and processes to be able to 'move with' the landscape and nurture the body/mind/spirit connection.

2/ The holistically oriented cross-cultural educators who participated in this study appeared to understand and work with complex dynamics more often than not, in a sensing way, in the sense that they seemed to prefer the process of feeling into situations, and employ their 
emotions and imagination and at times rational logic to 'move with' and 'move forward'. Their direction in general was not fixed in 'certain' outcomes, though it was 'certain' in an intuitive and felt sense. Their direction revolved around health and well-being: a being in relationship with oneself, with others, with the wider community and with the planet at large. Some more than others emphasised personal development, but all suggested that professional development cannot exclude a focus on the self: self-study is paramount.

3/ Participants approached the crux of the matter where the split is experienced, more often than not, in a 'blunt-rocking' effort as bricoleurs, in the sense that they embodied interdisciplinary boundaries and used creative methods, but not to create innovation necessarily. They suggested a change in attitude is much more important.

4/ the split in cross-cultural exchanges appeared to be contextualised as a web with associated dynamics. Whenever self-protection was not recognised a more 'passive' and 'fixed' approach was employed. Then, 'blind spots' were kept intact and there was no deep inquiry. The split was also contextualised in one-way communication styles that emphasise information, and not interpersonal communication and personal development. Though research-participants appeared to prefer two-way, organic, intuitive and creative forms of communication that emphasise interpersonal communication and personal development, the web's sometimes appeared too (socio-politically) attractive, possibly as part of the compulsion to self-protect in alignment with the group mind-dynamics. Similarly, to the degree holistically oriented cross-cultural educators (including myself) bought into 'boxed' thinking, and cause was seen as different from effect and contact with existential dynamics was cut.

5/ The greatest unknown influence appeared to be the group mind, largely because a concept that is rarely discussed in literature or the field of cross-cultural education at large.

6/ The web of relationships in which the split is either or not contextualised became particularly clear by focusing on the 'plek der moeite' [the area of difficulty] (Van Hoorn, $2007)^{\prime}$. In other words, by focusing on the friction at the centre of the cross, the web with associated dynamics was able to emerge. Employing the cross also revealed the 'web' in which the human psyche is interwoven in religiously/culturally imposed upon and negotiated 'building-blocks' -all part of the compulsion to self-protect: judgments, blames, expectations, attachments, significances, criticisms, finger pointings, protests, give aways, buy-ins, beliefs, viewpoints, intolerances, denials, assumptions and limitations.

7/ Wholesome life ecology (Dimitrov \& Naess, 2005) is an integral teaching/learning practice that is useful in cross-cultural contexts as it requires a looking within whilst looking outside. Assuming that what we see out there is a projection/reflection of what is 'in here', it requires a willingness to 'move with' and feel into interchanging dynamics to avoid single-paradigm myopia: it requires a whole sensory experience. But on one occasion, I was not able to participate in events that witnessed participants' application of a methodology that could be seen as associated with wholesome life ecology (WLE) to know the effects of their efforts in their field. This one occasion was too short in time to include in the analysis. However, if the

\footnotetext{
${ }^{1}$ Van Hoorn (2007a, pp. 135-136) expands on the idea 'the spot of difficulty' as presented by Kooistra (1988) and Wierdsma (1999), and refers to this 'spot' as that place where people invest more energy into differences in making meaning to create new meanings, by for example leaving space for intuition, experience, love and that which 'escapes words', and 'light emerges' (Van Hoorn refers to Simone Weil in this respect). At the centre of this 'spot' lies the willingness to truly hear and understand the other without really knowing where the interaction ends, and also asks from the other to enter into this space and be prepared to feel insecure.
} 
dynamics of the exchanges which took place among and between research-participants including myself, could be considered as reflective of a re-energised understanding among human beings and the ability to work with complex dynamics, then it was witnessed in the inner 'urge', the inner direction that drove the exchanges: an inner urge that created a sense of 'finding-oneself-in-relation' (Todres, 2007) whilst 'moving with' opposing dynamics.

8/ The study brought bring back to life an ancient universal symbol that, over time, has lost its dynamic meaning of hope and transformation. The cross proved to work as a medium, a facilitator of a dynamic flow that enables and propels humanity forward as it rehabilitates the self-in-relationship.

9/ It became clear that the knower of the lived experience (the sensory self) is able to observe and attend to complex dynamics whilst tinkering at the edges of paradigm- or boxed thinking. S/he operates as the bricoleur that appoints the rational mind for it to deal with unhandled emotions and Yang ways of processing (Capra, 1982). The knower of the lived experience opens up the gateway to the beyond boundaries and into the integral. S/he is in dialogue at the Centre of the Cross and conveys one to the other without attachment. S/he is in attendance to the moment of bifurcation in cross-cultural exchanges: the moment when there is an opportunity to go one way or another, depending on intention and focus of awareness. S/he employs currere (Eisner, 1972) because runs the course as s/he goes in the present moment. $\mathrm{S} /$ he observes the meetings and clashings between people and cultures as they self-organise as webs of relationships or a group mind.

\section{In conclusion}

In this paper I discussed that and how a focus on the metaphor or symbol CROSS reveals dynamics that pertain to cross-cultural education. This focus appears timely for its religious connotations that seem to powerfully affect world politics including globalising education.

I also discussed that cross-cultural education consists of its own dynamic that is a group mind in and of itself that is rarely acknowledged and subliminally reinforced. The current transition from industrialization to ecological thinking and the related meltdown of three disintegrating systems involving the economical, environmental and psycho-social requires the assistance of the knower of the lived experience to entice a shift out of this dynamic by attending to a deeper space of awareness including of the sensorial impact of shapes, signs and symbols. This knower enables the shift from an academic to an aesthetic mode of cognition (Thompson, 2004, p. ix).

A focus on the CROSS has demonstrated to stimulate a shift in cognition towards recognition. It also proved to give space to highly perceptive or sensitive people who are often side-lined in autocratic discourses. They - perhaps more than any others - need to free themselves from what others think (Hogeweg, 2011) as they transit into second tier stages of development.

For cross-cultural education as a whole, it remains to be seen whether it will move through and out of its own 'weerbarstigheid' so as to emerge from that what Apple (2006) refers to as the play-ground of victimhood as a powerful rhetorical device in the reinforcing of powerdynamics (p. 165). But the approach I took in this research could trigger a more collective awareness of the limitations of current ways of being and doing and how we are learn and teach to perceive and do research. This may assist an evolving cross-cultural education that includes and nurtures people's capacity to communicate on many more and subtler levels than hitherto accepted: communications that can be sensed but are difficult to put into words, 
yet excite a fresh space at the centre of cross-cultural exchanges as we draw a close to the final chapter in a book that was written in a most particular way.

And so another kind of story could emerge ... in the doing... in the being...

\section{REFERENCES}

Apple, M.W. (2006). Educating the "right" way: markets, standards, God, and inequality $\left(2^{\text {nd }}\right.$ ed.). New York: Routledge.

Beck, D.E. \& Cowan, C.C. (1996/2006). Spiral Dynamics: Mastering Values, leadership, and change. Oxford: Blackwell Publishing.

Benterrak, K., Muecke, S. \& Roe, P. (1984). Reading the Country: Introduction to Nomadology. Fremantle: Fremantle Arts Press.

Bethe, D. (2008). Application of my model to social conditions: Special Emphasis on public education in schools and mass media. Retrieved 10 September, 2008 from http://www.musicmind.com/applicat.htm,.

Bird Rose, D. (2008). On history, trees, and ethical proximity. Postcolonial Studies, 11(2), 157-167.

Bochner, A. (1997). It's about time: Narrative and the divided self. Qualitative Inquiry, 3(4), 418-438.

Bohm, D. (1996). On Dialogue. London: Routledge

Capra, F. (1982). The Turning Point: science, society and the rising culture. London: Fontana.

Carr, W. (2011). What is Second Tier? Powers and Perspectives Available to Leaders at Second Tier. Retrieved 23 June, 2011, from http://integralleadershipreview.com/2011/06/what-is-second-tier-powers-and perspectives-available-to-leaders-at-second-tier/

Chevalier, J. \& Gheerbrant, A. (1996). Dictionary of symbols. London: Penguin.

Cohen, J. (2001). The Complexity of Evolution. In W. Sulis \& I. Trofimova (Eds.), Nonlinear Dynamics in the Life and Social Sciences. IOS Press.

Dimitrov, V. (1998). Signs, Fractals and Dynamics. Retrieved 10 March, 2008, from http://members.tripod.com/ Vlad 36 7/Decision-Making-in Complexity.html\#mama17

Dimitrov, V. (2005). A New Kind of Social Science: Study of Self-Organization of Human Dynamics. Morrisville, NC: Lulu Press. 
Dimitrov, V. \& Naess, T. (2005). Wholesome Life Ecology: how to live wholesomely in a society that is killing the planet? Morrisville: Lulu Press.

Eisler, R. (2002). Partnership Education for the 21st Century. In J. Gidley \& S. Inayatullah, Youth Futures: Comparative Research and Transformative Visions (pp. 43-52). Westport, CT: Praeger.

Eisler, R. (2004). Education for the 21st Century: Keynote to 2004 HomeSchool Association of California Annual Conference. Retrieved 6 March 2007, from http://www.partnershipway.org/html/subpages/articles/homeschoolkeynote.htm

Eisner, E.W. (1972). Educating artistic vision. New York: Macmillan.

Eisner, E.W. (1979). The educational imagination: on the design and evaluation of school programs. New York: Macmillan.

Ellis, C. \& Bochner, A. (2000). Autoethnography, personal narrative, reflexivity: Researcher as subject. In N.K. Denzin \& Y.S. Lincoln (Eds.), Handbook of Qualitative Research (pp. 733-768). Thousand Oaks, CA: Sage Publications.

Gendlin, E.T. (1997). Carrying Forward: Gadamer and Gendlin on History, Language, and the Body. D.M. Levin (Ed): Language beyond Postmodernism: Saying and Thinking in Gendlin's philosophy (pp. 270-287). Evanston, Illinois: Northwestern University Press.

Gergen, M \& Jones, K. (2008). Editorial: A Conversation about Performative Social Science. Forum Qualitative Sozialforshung/Forum: Qualitative Research 9(2). Art. 43. North America 93105 2008. Retrieved 18 September, 2008, from http://www.qualitativeresearch.net/index.php/fqs/article/view/376/820

Gidley, J. (2007, April 17). The Evolution of Consciousness as a Planetary Imperative: An Integration of Integral Views. Integral Review, 5. Retrieved 28 May 2008, from http://integral-review.org/

Hamilton, M.L., Smith, L. \& Worthington, K. (2008). Fitting the Methodology with the Research: An exploration of narrative, self-study and autoethnography. Studying Teacher Education, 4(1), 17-28.

Hockey, J. \& Collinson, J.A. (2006). Seeing the way: Visual sociology and the distance runner's perspective. Visual Studies, 21(1), 70-81.

Hockey, J. (2006). Sensing the Run: The Senses and Distance Running. Senses \& Society, $1(2), 183-202$.

Hogeweg, L. (2011). Omgaan met Hoogevoeligheid [Dealing with High Sensitivity]. Spiegelbeeld, 6, 24-26). 
Kincheloe, J.L. \& Berry, K.S. (2004). Rigour and Complexity in Educational Research: Conceptualizing the bricolage. Maidenhead, England: McGraw-Hill Education.

Krishnamurti, J. (1978). The Wholeness of Life. London: Gollancz \& Harper Row.

Nussbaum, M. (2011). Educating for Profit, Educating for Freedom. Retrieved 22 August, 2011, from http://www.abc.net.au/religion/articles/2011/08/19/3297258.htm

Ormsby-Green, D. (2007a). A Better Way of Being. Mansfield, DC, Queensland: Jason Steensma.

Ormsby-Green, D. (2007b). A Journey of Discovery. Mansfield, DC, Queensland: Jason Steensma.

Schneider, G.W. (2008). Cinematic Ceremony: Toward a New Definition of Ritual. Visual Anthropology, 21(1), 1-17.

Sills, M. and Lown, J. (2008). The field of subliminal mind and the nature of being. European Journal of Psychotherapy \& Counselling, 10(1), $71-80$.

Smith, M. K. (2001). Chris Argyris: theories of action, double-loop learning and organizational learning. The encyclopedia of informal education. Retrieved 18 July, 2011, from http://www.infed.org/thinkers/argyris.htm

Storm, H. (1972). Seven Arrows. New York: Ballantine.

Tandon, S.N. (1995/2000). A Re-Appraisal of Patajali's Yoga-Sutras. Igatpuri (India): Vipassana Research Institute.

Thompson, W.I. (1996). Coming into Being: Artifacts and Texts in the Evolution of Consciousness. New York: St. Martin's.

Thompson, W.I. (2004). Self and Society: Studies in the Evolution of Culture. Exeter, England: Imprint Academic.

Todres, L. (2007). Embodied Enquiry: Phenomenological Touchstones for Research, Psychotherapy and Spirituality. New York: Palgrave MacMillan.

Van den Akker, Josina W.I.M. (2009). Understanding and working with the dynamics in cross-cultural education (doctoral dissertation). University of Western Sydney, Library Digital repository, publication number 8081/1959.7/40745, (http://handle.uws.edu.au:8081/1959.7/40745)

Van Hoorn, M. (2007). Aandacht: bron van verbinding [Attention: Source of connection]. Published PhD-dissertation, University for Humanistics, Utrecht, The Netherlands. Van Gorcum.

Walker, R. \& Sonn, C. (2010). Working as a Culturally Competent Mental Health Practitioner. N. Purdie, P. Dudgeon \& R. Walker (Eds): Working Together: 
Aboriginal and Torres Strait Islander Mental Health and Wellbeing Principles and Practice (pp. 157-180). Canberra: Australian Government Department of Health and Ageing. 